\title{
Changing needs for children and adults with spina bifida and hydrocephalus in Northern Ireland Marie McGonnell
}

Address: Medical Adviser, Association for Spina Bifida and Hydrocephalus, PO Box 132, Cushendall, County Antrim, BT44 0WA, UK

Email: Marie McGonnell - mariem@asbah.org

from 53rd Annual Meeting of the Society for Research into Hydrocephalus and Spina Bifida Belfast, UK. 24-27 June 2009

Published: 27 November 2009

Cerebrospinal Fluid Research 2009, 6(Suppl 2):S45 doi:10.1186/1743-8454-6-S2-S45

This abstract is available from: http://www.cerebrospinalfluidresearch.com/content/6/S2/S45

(c) 2009 McGonnell; licensee BioMed Central Ltd.

\section{Background}

The needs of persons born with Spina Bifida (SB) and/or Hydrocephalus $(\mathrm{H})$ may change with age. ASBAH has in response to this sought the views of persons with Spina Bifida (SB) and/or Hydrocephalus (H) on its Northern Ireland database, to identify what the different needs may be. The results indicate that with the transition from childhood to adulthood there is a change in the perceived need.

\section{Materials and methods}

Postal questionnaire sent out from ASBAH to all persons with SB and/or H on its Northern Ireland database.

\section{Results}

770 questionnaires were distributed and 134 (17\%) were returned. 98 adults (M:F 45:51) and 36 children (M:F 18:18) responded. The main issues raised by the adults were, personal care and support $(12.5 \%)$, problems with accessibility $(12.5 \%)$, increased benefits/better income (15\%0, transport difficulties $(20 \%)$, finding employment (5\%0, help socialising (12.5\%) and adaptations and equipment $(10 \%)$ Within the children's responses, the main issues identified were personal care and support $(17 \%)$, problems with accessibility $(17 \%)$, increased benefits $(17 \%)$, transport $(17 \%)$, better medical care $(10 \%)$, lack of friends $(10 \%)$, help socialising $(6 \%)$, and adaptations and equipment $(6 \%)$. In both groups, these needs were identified as areas where study days would be of benefit to both children, their parents and to adults.

\section{Conclusion}

This survey confirms that as persons born with SB and/or $\mathrm{H}$ move from childhood to adulthood there is a perceived change in their needs that has to be addressed. The changing need is a reflection of the difficulties in maintaining a position within society when born with Spina Bifida and/ or Hydrocephalus. It identifies areas where services should meet this changing need. 